\title{
Contribuições da Língua de Sinais para o desenvolvimento profissional dos docentes surdos: condições de trabalho e protagonismo profissional
}

\section{RESUMO}

Marta Rejane Proença Filietaz martafilietaz@hotmail.com orcid.org/0000-0001-6718-5677 Universidade Tecnológica Federal do Paraná, Curitiba, Paraná, Brasil

\begin{abstract}
Esta pesquisa tem como objetivo analisar como a Língua de Sinais contribui para constituição do desenvolvimento profissional do docente surdo. A metodologia escolhida para a realização deste estudo buscou os pressupostos teóricos pautados na pesquisa com abordagem qualitativa. Para tal, foram realizadas entrevistas semiestruturadas, passadas por um processo de tradução da Libras para o português escrito, com seis docentes surdos responsáveis pela disciplina de Libras em duas instituições Federais de Ensino Superior, sendo estas a Universidade Tecnológica Federal do Paraná (UTFPR) e a Universidade Federal do Paraná (UFPR). O reconhecimento da Língua de Sinais como língua da comunidade surda brasileira, significa uma mudança ideológica com relação aos sujeitos surdos que passam a ser reconhecidos como diferentes e pertencentes a uma comunidade linguística minoritária, e não apenas uma mudança metodológica do ensino e aprendizagem de uma língua. Segundo os participantes desse estudo, a mobilização dos movimentos surdos na luta pelo reconhecimento de seus direitos contribuiu fortemente para novos encaminhamentos, entre eles a elaboração e a efetivação de políticas públicas voltadas para as necessidades desses sujeitos.
\end{abstract}

PALAVRAS-CHAVE: Desenvolvimento Profissional. Docente Surdo. Língua Brasileira de Sinais (Libras). 


\section{INTRODUÇÃO}

No contexto internacional, as delimitações orientadoras para as políticas voltadas às pessoas com necessidades educativas especiais foram anunciadas na Conferência de Educação para Todos, realizada em Jomtien, na Tailândia, em 1990. Entretanto, tais políticas foram objeto de amplo debate na Conferência Mundial sobre Necessidades Educativas Especiais, ocorrida em 1994, em Salamanca, na Espanha, quando as grandes definições sobre o tema passaram a orientar as ações dos organismos internacionais, dos governos e da sociedade por meio da Declaração de Salamanca.

Estes importantes documentos originados do macro contexto internacional impulsionaram as políticas educacionais inclusivas brasileiras e passaram a garantir, no caso dos sujeitos surdos, o direito e o reconhecimento da Língua Brasileira de Sinais (LIBRAS) como meio legal de expressão e comunicação (BRASIL, 2005), conforme Lei Federal no 10.436/02 e Decreto no 5.626/05. Em decorrência disso, preconizaram o desenvolvimento de práticas de ensino nos espaços escolares que garantissem a educação bilíngue (BRASIL, 2005).

Em termos gerais, no caso brasileiro, a educação bilíngue para surdos considera que, inicialmente, estes devam desenvolver a Língua de Sinais como primeira língua (chamada de L1), nas relações sociais estabelecidas preferencialmente com surdos adultos, usuários da língua de sinais e participantes ativos do processo educacional de seus pares. Além disso, os surdos devem desenvolver a Língua Portuguesa na modalidade escrita como segunda língua (L2).

De modo geral, a literatura que discute a relação dos docentes surdos com suas histórias de vida ainda é escassa. O conhecimento dessas histórias é fundamental para que se entendam os caminhos, percursos e vivências desta parcela da população, principalmente no que tange à apropriação da Libras, a fim de que se possa reconhecer as possibilidades, dificuldades, os entraves enfrentados e, a partir disso, apontar novos direcionamentos para a educação dos surdos.

Com relação especificamente à disciplina de Libras, tema central deste trabalho, o Decreto no 5.626/05, Capítulo II, expõe que tal disciplina deve ser incluída como obrigatória, conforme apontado em seu artigo 3.․:

Art. 3 A Libras deve ser inserida como disciplina curricular obrigatória nos cursos de formação de professores para o exercício do magistério, em nível médio e superior, e nos cursos de Fonoaudiologia, de instituições de ensino, públicas e privadas, do sistema federal de ensino e dos sistemas de ensino dos Estados, do Distrito Federal e dos Municípios.

$\S 1$ oTodos os cursos de licenciatura, nas diferentes áreas do conhecimento, o curso normal de nível médio, o curso normal superior, o curso de Pedagogia e o curso de Educação Especial são considerados cursos de formação de professores e profissionais da educação para o exercício do magistério.

§ 2ㅇ A Libras constituir-se-á em disciplina curricular optativa nos demais cursos de educação superior e na educação profissional, a partir de um ano da publicação deste Decreto (BRASIL, 2005, s/p). 
Desse modo, é preciso reconhecer que a Libras, na última década, passou a circular nos meios acadêmicos e que o surdo, a partir disso, também começou a ser reconhecido na sua diversidade. Nesse contexto, conjetura-se a necessidade de uma discussão mais profunda a respeito da apropriação e da legalidade da Língua de Sinais, dos avanços para a educação dos sujeitos surdos e de seu desenvolvimento profissional.

Sob esse prisma, é necessário entender o processo de formação e desenvolvimento do sujeito surdo em uma relação com o que Marcelo Garcia (2009) referencia como o desenvolvimento profissional do docente. O autor destaca o processo como algo complexo que é influenciado pela escola e pela universidade, pelas reformas e contextos políticos, e que também integra o compromisso pessoal, a disponibilidade para aprender a ensinar, as crenças, os valores, o conhecimento sobre as matérias que os docentes ensinam e como as ensinam, as experiências passadas, assim como a própria vulnerabilidade profissional.

Nesse viés, é preciso considerar o que os professores surdos têm a dizer, em termos de suas memórias, seus dilemas, contradições e avanços, tendo em vista que estes constituem-se elementos fundamentais para a compreensão das possibilidades de seu desenvolvimento profissional docente. Disso se destaca a ideia de que o processo de aprendizagem dos docentes surdos se relaciona com suas experiências e expectativas, mas, sobretudo, com suas trajetórias de formação (inicial e continuada), com as ações políticas a que estão atrelados e com os espaços onde ocorrem suas práticas.

Nesse sentido foram selecionados seis professores surdos, recémconcursados, em duas Instituições de Ensino Superior (IES) públicas federais localizadas no Estado do Paraná, nas quais esses sujeitos assumem o protagonismo profissional e vivenciam inúmeros desafios decorrentes de sua inserção em um espaço que só recentemente abriu-se para a inclusão.

\section{MARCOS LEGAIS NA CONSTRUÇÃO DAS POLÍTICAS QUE ENVOLVEM A LIBRAS E O DESENVOLVIMENTO DO SUJEITO SURDO}

No contexto brasileiro, a Língua de Sinais foi oficializada como veículo de expressão e comunicação por meio da Lei no 10.436, de 24 de abril de 2002, sendo que tal marco propiciou novos direcionamentos na formação discente e docente e no reconhecimento pela sociedade das singularidades da comunidade surda.

O Decreto no 5.626, de 22 de dezembro de 2005 é considerado um marco na educação de surdos, pois regulamentou a Língua Brasileira de Sinais (Libras) como língua de instrução e previu adaptações na escola e no currículo, as quais impulsionaram um projeto educacional para surdos. Tal documento contém nove capítulos que discorrem a respeito da surdez e dos deficientes auditivos, da inclusão da disciplina de Libras nos cursos de graduação, da formação do professor e do instrutor de Libras, da difusão da condição bilíngue e pelo direito desta população comunicar-se em Libras em diferentes espaços sociais, da formação dos Tradutores e Intérpretes de Língua de Sinais (TILS), até a garantia de direito à educação e à saúde e o papel do poder público (BRASIL, 2005).

A partir desse decreto, um novo horizonte se apresentou, desde o direito dos surdos terem uma educação bilíngue, na qual o currículo lhes seja 
proporcionado em Língua de Sinais, até o ensino da Língua Portuguesa escrita como segunda língua, com a consequente adoção de "mecanismos alternativos para a avaliação de conhecimentos expressos em Libras" (Capítulo IV, Seção1, VII). Além disso, essa ordem determina um conjunto de medidas para serem cumpridas pelos cursos de formação de professores e pelas escolas de Ensino Fundamental, Médio e Superior, a fim de que a condição bilíngue da pessoa surda seja respeitada e o direito a processos de educação diferenciados lhes sejam garantidos com base em sua singularidade linguística (SOUZA, 2006, p. 269).

O Decreto no 5.626/2005 também enfatiza que "[...] as pessoas surdas terão prioridade" (BRASIL, 2005, s/p.), no que refere à formação para ministrar a disciplina de Libras. Caso "[...] não haja docente com título de pós-graduação ou de graduação em Libras para o ensino dessa disciplina em cursos de educação superior" (Idem, 2005, s/p.), deve ser ministrado por profissionais com perfis específicos, sendo que o professor bilíngue constitui um dos perfis aceitos, desde que tenha "pós-graduação ou formação superior e com certificado obtido por meio de exame de proficiência em Libras, promovido pelo Ministério da Educação" (Idem, 2005, s/p.).

Com relação à educação bilíngue, tal decreto salienta que:

Art. 22. As instituições federais de ensino responsáveis pela educação básica devem garantir a inclusão de alunos surdos ou com deficiência auditiva, por meio da organização de:

I - escolas e classes de educação bilíngue, abertas a alunos surdos e ouvintes, com professores bilíngues, na educação infantil e nos anos iniciais do ensino fundamental;

II - escolas bilíngues ou escolas comuns da rede regular de ensino, abertas a alunos surdos e ouvintes, para os anos finais do ensino fundamental, ensino médio ou educação profissional, com docentes das diferentes áreas do conhecimento, cientes da singularidade linguística dos alunos surdos, bem como com a presença de tradutores e intérpretes de Libras - Língua Portuguesa.

§ 1. São denominadas escolas ou classes de educação bilíngue aquelas em que a Libras e a modalidade escrita da Língua Portuguesa sejam línguas de instrução utilizadas no desenvolvimento de todo o processo educativo (BRASIL, 2005, s/p).

Cabe destacar que, assim como a Lei no 10.436/02, esse decreto impulsionou a política educacional inclusiva e garantiu aos sujeitos surdos o direito e o reconhecimento da Língua Brasileira de Sinais (LIBRAS) como meio legal de expressão e comunicação (BRASIL, 2002).

Ainda de acordo com o documento citado, atualmente nos cursos de licenciaturas há obrigatoriedade em ofertar a Libras como disciplina curricular, contemplando a educação inclusiva e o ensino dessa língua. Isso se replica também aos cursos de magistério em nível de Ensino Médio e cursos de Fonoaudiologia, conforme prevê o documento:

Art. 9o A partir da publicação deste Decreto, as instituições de ensino médio que oferecem cursos de formação para o magistério na modalidade normal e as instituições de educação superior que oferecem cursos de Fonoaudiologia ou de formação de professores devem incluir Libras como disciplina curricular, nos seguintes prazos e percentuais mínimos: I - até três anos, em 
vinte por cento dos cursos da instituição; II - até cinco anos, em sessenta por cento dos cursos da instituição; III - até sete anos, em oitenta por cento dos cursos da instituição; e IV - dez anos, em cem por cento dos cursos da instituição (BRASIL, 2005, s/p).

O processo de ordenamento legal, relacionado ao ensino da disciplina de Libras nos cursos de formação de professores, recebe uma deferência especial na recente Resolução no 2, de 1 o de julho de 2015, a qual institui as Diretrizes Curriculares Nacionais para a formação inicial em nível superior para os cursos de licenciatura, cursos de formação pedagógica para graduados e cursos de segunda licenciatura e para a formação continuada. $\mathrm{O}$ art. $3^{\circ} \S 60$ estabelece que:

\begin{abstract}
o projeto de formação deve ser elaborado e desenvolvido por meio da articulação entre a instituição de educação superior e o sistema de educação básica, envolvendo a consolidação de fóruns estaduais e distrital permanentes de apoio à formação docente, em regime de colaboração, e deve contemplar que [...] V - a ampliação e o aperfeiçoamento do uso da Língua Portuguesa e da capacidade comunicativa, oral e escrita, como elementos fundamentais da formação dos professores, e da aprendizagem da Língua Brasileira de Sinais (Libras) (BRASIL, 2015, p. 05).
\end{abstract}

Portanto, ao situar os marcos legais que delimitam a Libras no contexto educacional brasileiro, fica evidente que estes acabam por orientar ações e propostas quanto aos processos formativos e de atuação dos profissionais, em especial do sujeito surdo. Tais propostas podem ser percebidas no enfoque da formação e atuação de profissionais numa perspectiva de educação bilíngue.

\title{
O PROFESSOR DE LIBRAS: O DESAFIO DOS PROFESSORES SURDOS
}

Com relação ao professor de Libras, o Capítulo III do Decreto no 5.626/2005, determina em seu art. 4 ㅇ que,

\footnotetext{
a formação de docentes para o ensino de Libras nas séries finais do ensino fundamental, no ensino médio e na educação superior deve ser realizada em nível superior, em curso de graduação de licenciatura plena em Letras: Libras ou em Letras: Libras/Língua Portuguesa como segunda língua (BRASIL, 2005, p. 03).
}

No contexto educacional, a figura do professor surdo de Libras é nova, e em termos processuais e históricos a inserção desse profissional coincide com o ingresso dos surdos no Ensino Superior e com o teor do art. 5o do documento citado acima:

\begin{abstract}
A formação de docentes para o ensino de Libras na educação infantil e nos anos iniciais do ensino fundamental deve ser realizada em curso de Pedagogia ou curso normal superior, em que Libras e Língua Portuguesa escrita tenham constituído línguas de instrução, viabilizando a formação bilíngue.
\end{abstract}

$\S 1$ 1 Admite-se como formação mínima de docentes para o ensino de Libras na educação infantil e nos anos iniciais do ensino fundamental, a formação ofertada em nível médio na modalidade normal, que viabilizar a formação bilíngue (BRASIL, 2005, p. 03). nesta pesquisa, cabe esclarecer que as Instituições de Ensino Superior (IES) vêm se 
organizando, gradativamente, para a inserção dos professores surdos para o ensino da disciplina de Libras com o objetivo de atender às especificações do Decreto no 5.626/2005, uma vez que os arts. 7.ㅇ e 8.ㅇ desse documento orientam que nos próximos dez anos, caso não haja docente com título de pós-graduação ou de graduação em Libras para o ensino dessa disciplina em cursos de Educação Superior, ela poderá ser ministrada por profissionais que apresentem pelo menos um dos seguintes perfis:

I - professor de Libras, usuário dessa língua com curso de pós-graduação ou com formação superior e certificado de proficiência em Libras, obtido por meio de exame promovido pelo Ministério da Educação;

II - instrutor de Libras, usuário dessa língua com formação de nível médio e com certificado obtido por meio de exame de proficiência em Libras, promovido pelo Ministério da Educação;

§ 2o A partir de um ano da publicação deste Decreto, os sistemas e as instituições de ensino da educação básica e as de educação superior devem incluir o professor de Libras em seu quadro do magistério.

Art. 8ㅇ 0 exame de proficiência em Libras, referido no art. 7으 deve avaliar a fluência no uso, o conhecimento e a competência para o ensino dessa língua (BRASIL, 2005, s/p).

Filietaz e Tsukamoto (2013) mencionam que a Universidade Federal de Santa Catarina (UFSC), em 2006, começou a ofertar o curso à distância de licenciatura em Letras-Libras. O propósito do curso é capacitar professores para atuar como docentes de Libras. De início, a UFSC ofertou esse curso em nove polos de ensino e para quatrocentos e noventa e cinco (495) alunos, dando preferência às pessoas surdas. Em 2008, foi incluída a habilitação de bacharel em Tradução e Interpretação de Língua de Sinais. Um ano depois, começou o curso presencial de Letras-Libras na UFSC. Como um fato histórico, os alunos surdos que ingressaram no curso concluíram a licenciatura em Letras-Libras no ano de 2010.

Em 2015, a Universidade Federal do Paraná (UFPR), campus Curitiba, iniciou a oferta do Curso de Letras/Libras na modalidade presencial. O processo seletivo para tal curso foi realizado por meio de uma prova em Língua Brasileira de Sinais (Libras), visualizada a partir de vídeos. O Letras/Libras consiste em um curso de graduação, com opção de licenciatura, para quem quer ensinar Libras, conforme previsto no Decreto $n=5.626 / 2005$. Já o profissional formado em Bacharelado em Letras-Libras, este poderá atuar como intérprete em salas de aula, em reuniões e conferências, na tradução de textos técnicos e literários e na revisão e preparação de textos (BRASIL, 2005).

Na discussão sobre a trajetória de vida dos sujeitos surdos, faz-se necessário atentar para suas necessidades e dificuldades linguísticas. Atualmente, considerase que a língua de instrução para esses sujeitos seja a Língua de Sinais. Nessa perspectiva discute-se as memórias dos sujeitos surdos quanto às contribuições da Língua de Sinais para seu desenvolvimento profissional. 
Os seis professores surdos participantes da pesquisa passam a ser identificados com o nome de Estrelas, de modo a preservar suas identidades. Assim, ganham destaque "as vozes silenciosas" das Estrelas: Sirius, Alfa Centauri, Arcturus, Canopus, Vega e Capella.

Para os indivíduos surdos, além das exigências do mercado de trabalho, ainda acrescenta-se a barreira de comunicação, que em diversas situações configura-se em restrições. No entanto, cabe ressaltar que a acessibilidade profissional proporciona ao surdo sua valorização como cidadão e leva à efetivação dos seus direitos garantidos em lei. É preciso perceber as potencialidades dessas pessoas e abrir-lhes as portas do mundo do trabalho, independentemente da limitação ou da situação na qual se encontram. O processo de pensar e buscar a acessibilidade perpassa pela oferta de possibilidades a partir das quais a igualdade de direitos, a dignidade e o respeito às diferenças devem configurar-se como marcos significativos e concretos.

Nesse contexto, considerando a relevância que a acessibilidade profissional representa para o sujeito surdo, busca-se analisar as falas dos participantes da pesquisa em relação às condições de trabalho, no espaço da Universidade, e seu protagonismo profissional.

\section{DISCUTINDO SOBRE AS CONDIÇÕES DE TRABALHO DO DOCENTE SURDO}

O ambiente comunicativo e de interação no trabalho é imprescindível para a inserção do surdo. É importante destacar a comunidade surda, como um grupo social minoritário que carrega em sua história situações de segregação e exclusão social. Assim, ainda hoje a maioria dos surdos não alcança o Ensino Superior, fato que difere dos surdos entrevistados neste estudo.

A falta de oportunidades para o desenvolvimento acadêmico pode, em um primeiro momento, ser um elemento que oportuniza a segregação de muitos sujeitos surdos que trabalham como mão de obra não especializada em empresas de pequeno, médio ou grande porte.

Como bem aponta a Estrela Alfa Centauri, o surdo assume, muitas vezes, a função de auxiliar de produção mesmo tendo formação universitária:

\footnotetext{
conheço vários surdos com formação em outras áreas tais como designers, engenheiros, psicólogos, fisioterapeutas e administradores. Esses profissionais acabam por trabalhar nas empresas onde existem cotas para deficiências (ESTRELA ALFA CENTAURI).
}

Dessa forma, constata-se que um percentual mínimo consegue seu espaço no mundo do trabalho em sua área de formação específica. A Federação Nacional de Educação e Integração dos surdos (FENEIS) busca a efetivação do direito de inserção dos surdos por meio da Lei Federal no 8.213/91, que assegura a inserção das pessoas com necessidades especiais no mercado de trabalho. Nessa concepção, a FENEIS (2010) considera que o percentual de $5 \%$ das vagas em concursos públicos garantindo a participação das pessoas com de deficiência e com necessidades educativas especiais na busca de colocação profissional tem sido outra forma de ver respeitados os direitos trabalhistas dos surdos.

No entanto, às condições de trabalho para o surdo ainda que a legislação aponte para situações que possibilitam sua inserção no mercado de trabalho, o 
que de fato ocorre é que a maioria das empresas reconhece esse direito e contrata os surdos em seus quadros funcionais, porém parece que só fazem isso para atender a uma exigência exposta na lei. Tais empresas não estão aptas a receber esses trabalhadores, não contratam intérpretes para acompanhá-los, nem instrutores de Libras para atuarem na formação dos demais trabalhadores ouvintes e para garantir a efetiva comunicação entre os surdos e os demais colegas.

Segundo Novaes (2010), em decorrência dessa falha, constata-se uma subutilização dos trabalhadores surdos no contexto das empresas, que deixam de atuar como trabalhadores qualificados, dentro de suas áreas de formação (seja técnica ou superior), para atuarem em situações laborais aquém de suas capacidades. Portanto, o que ocorre na prática é uma verdadeira segregação, em que os trabalhadores surdos são postos de lado e até mesmo ignorados dentro de seus locais de trabalho. Tais situações acabam contribuindo para que os surdos sintam-se subestimados por si, pela família, pelos colegas de trabalho, pelos amigos e até mesmo pelos próprios chefes (NOVAES, 2010).

No caso dos professores surdos, partícipes deste estudo, a inserção profissional no âmbito da Educação Superior pode ser percebida a partir de um movimento intenso no que se refere às garantias legais de atuação do surdo nas licenciaturas, o que se concretiza também no caso de docentes que atuam no nível da Educação Básica. Contudo, para que esses profissionais exerçam um papel fundamental nos processos de desenvolvimento e aceitação social dos próprios surdos, é necessário que tenham clareza de que o seu trabalho tem um alcance para além da sala de aula. Segundo afirma a Estrela Sirius:

é muito importante que o professor seja licenciado. Ter conhecimento sobre o desenvolvimento psicológico e pedagógico da criança, da estrutura gramatical da Libras e ter uma postura correta de educador (ESTRELA SIRIUS).

Nesse panorama, é necessário considerar que somente ser fluentes em Língua de Sinais não lhes dará condições de exercer seu trabalho com qualidade, mas é na interação como o outro e produzindo novos conhecimentos por meio de pesquisas, de projetos, de ações de extensão e de aproximação com a comunidade que efetivamente será possível um desenvolvimento melhor do seu trabalho. A esse respeito Behrens e Carpim (2013, p. 116) esclarecem que "os professores precisam buscar as novas demandas educacionais e sociais, concebendo sua prática educativa [...] orientando ao fazer dialógico, inovador onde o ensino seja proposto por meio da pesquisa".

Ao discutir a questão da qualidade da formação docente e da abrangência desta, Ferreira (2006, p. 3648) situa que:

\footnotetext{
Uma formação de qualidade ou sem qualidade exercerá uma influência relevante sobre a possibilidade ou impossibilidade de acesso às oportunidades sociais da vida em sociedade, possibilidade ou impossibilidade de acesso à cidadania.
}

Na fala da Estrela Sirius e Capella ficam explícitas a importância de uma formação de qualidade para os professores surdos, em especial quando se trata de sua atuação na disciplina de Libras: 
Atualmente a formação dos professores surdos para atuação na disciplina de Libras está bem melhor, está mais estruturada, mas os cursos estão ainda em construção. 0 próprio professor já entra motivado para estudar, tem mais acesso a leitura e com isso o avanço e o progresso são rápidos. Já percebi muitos surdos tentando ingressar na carreira do magistério, mas falta base (ESTRELA SIRIUS).

A formação específica é muito importante e o curso de Letras Libras dá essas condições, pois ensina a metodologia, estratégias, como utilizar e elaborar recursos pedagógicos. (ESTRELA CAPELLA).

A qualidade da formação desse profissional possibilitará também que ele desenvolva estratégias para transpor as barreiras de comunicação encontradas na universidade, tanto com os demais professores como também durante as aulas com os alunos ouvintes.

$\mathrm{Na}$ fala das Estrelas Arcturus e Canopus, destacam-se as estratégias criadas por elas, como a criação de cursos para professores e os recursos visuais usados durantes as aulas com ouvintes, a fim de que a Libras seja disseminada em todos os ambientes da universidade. Tal qual aponta Behrens e Carpim (2013, p. 115), "[...] cabe ao professor assumir o compromisso de atuar além da dimensão técnica, compondo também em seu trabalho educativo a dimensão social, despertando a criatividade e criticidade do aluno [...]". O educador necessita refletir sobre sua prática pedagógica, levando em conta os aspectos sociais e culturais dos sujeitos envolvidos. Assim se posicionam esses sujeitos:

No meu trabalho na Universidade, ainda existe uma barreira de comunicação, embora tenha havido progresso, pois já aprenderam um pouco de sinais. Já fiz projeto para ofertar curso de Libras básico para os professores a partir de 2015 e isso, com certeza, contribuirá para mudar a realidade atual (ESTRELA ARCTURUS).

Em minhas aulas, na disciplina de Libras, uso muitos recursos visuais, atividades com imagens, vídeos e dramatizações. Comunico-me através de email e da escrita com os alunos ouvintes. No primeiro dia trago intérprete comigo para esclarecer regras, o plano de ensino, as avaliações, etc. (ESTRELA ARCTURUS).

A comunicação do professor surdo com os alunos ouvintes no início é difícil. No primeiro dia de aula, os ouvintes não conhecem a Língua de Sinais e o professor deverá usar diferentes recursos visuais, como escrever no quadro, mostrar slides, usar alfabeto manual e apresentar diferentes formas de atividades. Isso deve acontecer com muita calma e com a interação do grupo. O professor deve ser apenas o mediador (ESTRELA CANOPUS).

A definição de estratégias de ensino, por parte dos professores surdos com o intuito de favorecer a aprendizagem da Libras aos seus alunos ouvintes, pode ser destacada como elemento indispensável a um profissional qualificado. Assim, ter conhecimento teórico, metodológico e linguístico é condição fundamental para que ocorra o diálogo entre o ensino e a aprendizagem, considerando que os estudantes universitários com os quais os professores surdos interagem são ouvintes e não possuem, via de regra, um conhecimento prévio da Libras.

Nas memórias da Estrela Sirius, constata-se que no ambiente onde atua como docente existe uma possibilidade maior de diálogo, pois pode contar com outro docente surdo e com o Tradutor e Intérprete de Língua de Sinais, promovendo a interação e a participação em diferentes contextos na universidade 
e com os demais colegas ouvintes. Oliveira e Santos $(2007$, p. 118) ponderam que "o diálogo, por isso mesmo, não nivela, não reduz um ao outro. Nem é favor que um faz ao outro. [...] Implica, ao contrário, um respeito aos sujeitos nele engajados". Essa possibilidade de interação dialógica contribui para seu acesso aos conhecimentos científicos e ao conhecimento de mundo.

Assim relata a Estrela Sirius:

Na universidade onde trabalho somos duas professoras de Libras. Sempre conversamos e trocamos ideias sobre as disciplinas. Nas reuniões com os professores ou sobre as disciplinas pedagógicas, sempre discutimos sobre como melhorar a disciplina, articular com as outras. Todos no departamento respeitam minhas colocações. Temos interpretes nas reuniões e isso facilita o diálogo (ESTRELA SIRIUS)

O professor surdo desempenha um papel fundamental para a efetiva inserção do sujeito surdo para que este tenha acesso aos bens culturais, às informações, bem como a garantia de admissão nos espaços profissionais em todas as esferas da sociedade. Portanto é fundamental que se tenha a consciência da busca constante de formação e da necessidade de conquistar seu espaço no ambiente acadêmico e de trabalho.

\section{PROTAGONISMO PROFISSIONAL}

Considerando o pressuposto de que a formação do docente surdo concretiza-se a partir de aspectos relacionados a sua compreensão do que é "ser professor", faz-se necessário ponderar algumas características que envolvem a atuação do profissional docente: o desenvolvimento de uma visão crítica sobre perspectivas teóricas, uma postura acadêmico-científica, o exercício profissional, didático e pedagógico e o domínio dos conteúdos pedagógicos - teóricos e práticos - que permitam a construção dos conhecimentos relativos aos diferentes níveis de ensino e a atuação consciente e autônoma na busca de uma formação continuada e abrangente.

Uma vez que o saber profissional do professor não pode limitar-se ao mero domínio de um conjunto de conhecimentos científicos articulados aos conteúdos curriculares, é preciso atentar para o fato de que a construção de seu saber profissional resulta de uma mobilização complexa, organizada e coerente. Todos esses conhecimentos se efetivam em torno de cada situação educativa concreta, no sentido do alcance do objetivo definidor da ação profissional, ou seja, a aprendizagem do aluno (ROLDÃO, 2005).

Os aspectos apontados anteriormente estão presentes nas falas da Estrela Canopus e da Sirius, que assim se reportam a sua prática profissional docente:

O professor surdo terá que dominar a teoria que envolve não só a educação dos surdos, mas também a Língua de Sinais. Ele precisa pesquisar, estudar e conhecer o significado dos sinais, contextualizar e é desta forma que ele terá confiança e domínio para ensinar os conteúdos. Deverá conhecer os acontecimentos do mundo e no mundo. Deverá ser capaz de trabalhar com diferentes recursos visuais. Antes de ir para a sala de aula deverá planejar, organizar o conteúdo a ser ensinado (ESTRELA CANOPUS). 
elaborando vídeos e apostilas. Já temos dois bolsistas. Fazemos reuniões para discutirmos todo o processo. Estou envolvida com diferentes trabalhos e tenho um bom relacionamento no meu departamento (ESTRELA SIRIUS).

A autonomia desses profissionais necessita estar atrelada ao campo de pesquisa, pois dessa forma participarão do contexto geral da Instituição de Ensino Superior onde estão inseridos e nos demais níveis de ensino. Conforme aponta um dos sujeitos da pesquisa:

Agora, formada como professora poderia auxiliar melhor os professores do ensino regular. Estando em uma universidade poderia elaborar mais materiais sobre Libras e disseminá-los (ESTRELA SIRIUS).

Portanto, quanto maior o envolvimento e a participação em intervenções pedagógicas em diferentes níveis de ensino, maior será seu protagonismo. 0 professor-pesquisador se mantém atualizado, prioriza a pesquisa em detrimento do ensino e investiga sua prática docente. É importante considerar que as pesquisas relacionadas à área são ainda restritas e, com isso, é indiscutível a relevância de novas pesquisas ainda mais sendo desenvolvidas pelos próprios protagonistas da história. A esse respeito as Estrelas Canopus e Vega e firmam que:

O início do trabalho como professor de Libras é bem difícil. Devido a inexperiência, dá uma sensação de medo, de vergonha, de insegurança em não ser entendido. Com o tempo vamos nos acostumando, interagindo, dialogando e superando. Depois de alguns anos você sabe que precisa pesquisar, se inteirar das informações, o que está acontecendo, quais os fatos principais que estão sendo discutidos na mídia (ESTRELA CANOPUS).

Quando fiz a Licenciatura em Matemática, não pensava que seria professor de Libras. Sempre amei essa profissão, pois acredito que tenha sensibilidade para atuar com professor. Conheço quando o aluno está interessado na aula, quando ele interage. Percebo quando estão avançando, progredindo em língua de sinais e se estou atingindo o objetivo de ensinar, pois é através do interesse e empenho dos alunos que consigo avaliar meu desempenho (ESTRELA CANOPUS).

Comecei a lecionar no ano 2000. No começo com muita vergonha, pois as plateias eram grandes, mas depois fui percebendo o interesse dos alunos ouvintes e isso me encorajou a continuar. Aprendi que tinha que contextualizar e não apenas trabalhar com palavras isoladas e a partir daí fui me desenvolvendo. Estudei muito o livro "Libras em contexto", fiz apostilas e criei muitos materiais. Com isso fui me acostumando (ESTRELA VEGA).

A partir dos relatos acima, é possível visualizar a importância da formação de um professor quando este é capaz de analisar sua prática e, por meio dessa análise, aprimorar sua prática pedagógica, contribuindo para que os alunos não sejam somente receptores de informações, de forma mecânica e alienada, mas para que desenvolvam uma consciência mais crítica que os leve a questionar e refletir a respeito de suas ações. Esse exercício constante encontra ressonância naquilo que Freire (1985) defende de que o indivíduo deve saber sobre a sua realidade para só então buscar transformá-la.

O professor necessita considerar seu papel como professor em suas atividades cotidianas e, a partir de então criar oportunidades para que atinja sua autonomia intelectual. Desse modo, em algumas falas acima é possível perceber que os sentimentos de vergonha e insegurança foram substituídos pela confiança 
e autonomia, na medida em que estes profissionais foram estudando e pesquisando a respeito de seus papéis como professores de Libras.

Com relação às atividades de pesquisa, as quais são fundamentais nos meios acadêmicos, as Estrelas Sirius, Vega e Arcturus afirmam:

\begin{abstract}
Atualmente na minha atuação como docente na disciplina de Libras na universidade já iniciei um núcleo de pesquisa com o objetivo de elaborar materiais, tradução para a libras, de livros específicos sobre educação de surdos. É muito importante ter a oferta de livros na versão em libras, pois o surdo terá oportunidade de conhecê-lo na Libras e na Língua Portuguesa na modalidade escrita (ESTRELA SIRIUS).
\end{abstract}

Na Universidade o grupo de professores surdos trabalham com vários projetos de pesquisa. Temos interpretes que colaboram, fazem correções no texto e nos auxiliam. Falamos em língua de sinais e o intérprete transcreve para a língua portuguesa escrita. Possuímos nosso espaço e somos livres para criar projetos (ESTRELA VEGA).

$\mathrm{Na}$ universidade onde trabalho apresentamos a proposta do curso de licenciatura em Letras Libras. Meu projeto de iniciação cientifica já foi aprovado e a proposta é elaborar curso de formação dos instrutores surdos, orienta-los sobre diferentes metodologias para ensinar crianças surdas. (ESTRELA ARCTURUS).

É importante ressaltar que o professor-pesquisador, ao problematizar, analisar e compreender suas práticas direciona o processo de transformação estabelecendo novas possibilidades de ação sobre sua docência, dando visibilidade a concepções que contextualizam os debates sobre os surdos e sua educação. Portanto, nas falas acima é possível visualizar que esses participantes estão exercendo seus papéis enquanto professores pesquisadores.

Em sua atuação profissional na Educação Superior o professor surdo poderá contribuir de modo significativo para que os acadêmicos ouvintes conheçam a Libras e, para além disso, também passem a reconhecer a identidade surda e as lutas dessa comunidade nos distintos espaços políticos e sociais. Enquanto docentes comprometidos, estarão inclusive situando suas histórias de vida, de lutas e as perspectivas desse grupo social.

O protagonismo do docente surdo exige que este perceba que existe um mundo fora do espaço da universidade, o que é indispensável para que pense e planeje suas práticas, sempre atento ao que se passa em contextos extramuros. A esse respeito, as discussões no próximo tópico tratam da acessibilidade social, quando então o sujeito surdo pode articular sua prática e sua interação com a sociedade.

É possível perceber que o curso de licenciatura em Letras/Libras possibilitou para os entrevistados o conhecimento aprofundado da Língua de Sinais e permitiu suas qualificações profissionais como docentes surdos. Frente à constatação de 
que cinco dos seis participantes frequentaram o curso de Letras/Libras, é plausível afirmar que este curso e o próprio Decreto Federal n.o 5.626/2005 propiciam, por meio da Língua de Sinais, um melhor envolvimento e adaptação à vida acadêmica e também o entendimento e o domínio dos conteúdos pedagógicos. É notório que essa conquista contribuiu para a constituição desses sujeitos surdos, oportunizando-os um amplo desenvolvimento e colaborando com sua inserção profissional.

Ainda que persistam enormes obstáculos no que diz respeito ao desenvolvimento do surdo, como a ausência do tradutor e de intérpretes, a falta de formação dos professores em Libras e as equivocadas abordagens em relação à educação desse grupo. Os participantes da pesquisa destacam que a apropriação da Língua de Sinais contribuiu para o reconhecimento e as construções de sentidos de mundo e para a ampliação do conhecimento acadêmico do sujeito surdo.

No caso dos professores surdos, em sua atuação no espaço das universidades federais, há uma sinalização de condições favoráveis à presença e ao reconhecimento destes profissionais. Contudo, deve-se considerar que no âmbito da educação superior já há algum tempo observa-se uma dinâmica de estruturação para atender aos dispositivos de inclusão expostos na legislação educacional.

Nessa perspectiva, incluem-se a presença dos intérpretes e de um corpo docente consciente de que esta minoria linguística é tão capaz quanto a maioria ouvinte, desde que thes sejam dadas as mesmas oportunidades e condições específicas para que possam ter reconhecimento academicamente tanto quanto os demais docentes.

O protagonismo profissional do docente surdo participante deste estudo se explicita a partir do tripé que envolve o ensino, a pesquisa e a extensão, como prática indissociável ao contexto da universidade. A prática da pesquisa dá base às intervenções no ensino, e a extensão pode ser compreendida, portanto, como condição de alcance social do protagonismo, no qual o professor, por meio de projetos e de ações concretas, poderá difundir a Libras e as práticas dos sujeitos surdos. Contudo, todas essas possibilidades de ação do professor surdo em seu espaço de atuação acadêmica precisam ser balizadas em um processo de construção dialógica ou, então, como bem define Freire (1985), pode-se correr o risco de se trabalhar com uma interpretação ingênua da realidade, notadamente projetada em instrumentos de dominação.

Tendo em vista a importância do tema, foi possível, por meio das memórias dos seis participantes da pesquisa, vislumbrar caminhos pedagógicos mais efetivos para o ensino da Língua de sinais. No entanto, sugere-se a realização de mais estudos de modo que outras realidades nacionais também possam ser vislumbradas tanto nos âmbitos público quanto privado.

\section{Contributions of sign language for the deaf teachers ' professional development:}




\title{
working conditions and professional leadership
}

\begin{abstract}
This research aims to analyze how the sign language contributes to the professional development of teaching deaf, enabling access to goods/resources and services available in the spheres of education, professional and social. The methodology chosen for the accomplishment of this study sought the theoretical assumptions based on research with qualitative approach. Semi-structured interviews were made, passed through a process of translation from Portuguese pounds for the written, with six deaf teachers responsible for discipline in two federal institutions of higher education, being these the Federal Technological University of Paraná (UTFPR) and the Federal University of Paraná (UFPR). The recognition of sign language as the language of the deaf community, brazilian means an ideological change with respect to the deaf that are recognized as different and belonging to a linguistic minority community, and not just a methodological change in the teaching and learning of a language. According to the participants of this study, the mobilization of deaf movements in the fight for recognition of their rights contributed heavily to new referrals, including the preparation and execution of public policies geared to the needs of these subjects.
\end{abstract}

KEYWORDS: Professional Development. Teacher Deaf. Brazilian sign language (Libras). 


\section{Contribuciones de lengua de signos para el desarrollo profesional de los maestros sordos: las condiciones de trabajo y liderazgo profesional}

\section{RESUMEN}

Esta investigación pretende analizar cómo la lengua de signos se contribuye al desarrollo profesional de docentes sordo, permitiendo acceso a bienes y recursos y servicios disponibles en los ámbitos de la educación, profesional y social. La metodología escogida para la realización de este estudio buscó los supuestos teóricos basados en la investigación con enfoque cualitativo. Se realizaron entrevistas semiestructuradas, pasaron por un proceso de traducción de Portugués libras para el escrito, con seis profesores sordos responsables de disciplina en dos instituciones federales de educación superior, siendo estas la Universidad tecnológica Federal de Paraná (UTFPR) y la Universidad Federal de Paraná (UFPR). El reconocimiento de lengua de señas como la lengua de la comunidad sorda, Brasil significa un cambio ideológico con respecto a los sordos que son reconocidos como diferentes y pertenecientes a una comunidad lingüística minoritaria y no sólo un cambio metodológico en la enseñanza y el aprendizaje de una lengua. Según los participantes de este estudio, la movilización de movimientos sordas en la lucha por el reconocimiento de sus derechos contribuidos pesadamente a nuevas referencias, incluyendo la preparación y ejecución de políticas públicas orientadas a las necesidades de estos sujetos.

PALABRAS-CLAVE: Desarrollo professional. Maestro de sordos. Lengua de signos brasileña (Libras). 


\section{REFERÊNCIAS}

BEHRENS, M. A; CARPIM, L. A formação dos professores de educação profissional e o desafio do paradigma da complexidade. In: PRYJMA, Marielda (Org.). Desafios e trajetórias para o desenvolvimento profissional docente. Curitiba: Ed. UTFPR, 2013.

BRASIL. MEC. Ministério da Educação. Secretaria de Educação Especial. Lei № 10.436, de 24 de abril de 2002. Dispõe sobre a Língua Brasileira de Sinais LIBRAS e dá outras providências. Brasília, 2002.

BRASIL. Decreto n. 5.626 - Regulamenta a Lei no 10.436, de 24 de abril de 2002, que dispõe sobre a Língua Brasileira de Sinais - Libras, e o art. 18 da Lei no 10.098, de 19 de dezembro de 2000. Brasília, 2005.

BRASIL. Conselho Nacional de Educação. Resolução CNE/CP n. 02/2015, de 1 o de julho de 2015. Define as Diretrizes Curriculares Nacionais para a formação inicial em nível superior (cursos de licenciatura, cursos de formação pedagógica para graduados e cursos de segunda licenciatura) e para a formação continuada. Brasília, 2015.

FENEIS - FEDERAÇÃO NACIONAL DE EDUCAÇÃO E INTEGRAÇÃO DOS SURDOS. Que educação nós surdos queremos. Documento 008561/1999 elaborado pela Comunidade Surda no V Congresso Latino de Educação Bilíngue. Porto Alegre: UFRGS, abril 2010.

FERREIRA, N. S. C. Políticas de Formação de Profissionais da Educação: a imprescindibilidade da concepção de gestão. Anais do VI EDUCERE - Congresso de Educação da PUCPR, Curitiba: Champagnat, 2006. Disponível em: http://www.pucpr.br/eventos/educere/educere2006/anaisEvento/docs/PL344.pdf. Acesso em: 12 mar. de 2016.

FILIETAZ, M. R. P.; TSUKAMOTO, N. M. S. O Processo Seletivo do Professor Surdo da Universidade Tecnológica Federal do Paraná. Anais do VIII Encontro da Associação Brasileira de Pesquisadores em Educação Especial, Londrina: UEL 2013. Disponível em: http://www.uel.br/eventos/congressomultidisciplinar/pages/arquivos/anais/201 3/AT06-2013/AT06-002.pdf. Acesso em: 16 mar. 2016

FREIRE, P. Pedagogia do oprimido. 14a Ed. São Paulo: Editora Paz e Terra S/A, 1985. 
MARCELO GARCIA, C. Desenvolvimento profissional: passado e futuro. Sísifo Revista das Ciências da Educação, n. 8, p. 7-22, jan./abr. 2009. Disponível em: http://www.fep.porto.ucp.pt/sites/default/files/files/FEP/SAME/docs/Carlosmar celo Desenv Profissional.pdf. Acesso em: 12 mar. de 2016.

NOVAES, E. C. Surdos: educação, direito e cidadania. Rio de Janeiro: Wak, 2010.

OLIVEIRA, I. A.; SANTOS, T. R. L. A cultura amazônica em práticas pedagógicas de educadores populares. - PPGED / UEPA. PPGED /UEPA -GT. Educação Popular n.6, 2007. Disponível em: http://www.anped.org.br/sites/default/files/gt063039-int.pdf. Acesso em: 12 mar. de 2016.

ROLDÃO. M. C. Formação de professores, construção do saber profissional e cultura da profissionalização: que triangulação?. In: ALONSO, L.; ROLDÃO, M. C. (Coord.). Ser professor do 10 ciclo: construindo a profissão. Coimbra: Almedina, 2005.

SOUZA, R. M.; SILVESTRE, N. Educação de surdos: pontos e contrapontos. São Paulo: Summus, 2006

Recebido: 01 jun. 2016

Aprovado: 23 jun. 2016

DOI: $10.3895 /$ rtr.v1n1. 4022

Como citar: FILIETAZ, M. R. P. Contribuição da Língua de Sinais para o desenvolvimento profissional dos docentes surdos: condições de trabalho e protagonismo profissional. R. Transmutare, Curitiba, v. 1, n. 1, p. 54-70, jan./jun. 2016. Disponível em: <https://periodicos.utfpr.edu.br/rtr>. Acesso em: XXX.

Correspondência:

Marta Rejane Proença Filietaz

Av. Sete de Setembro, 3165, Rebouças, Curitiba, PR, Brasil, CEP 80230-901.

Direito autoral: Este artigo está licenciado sob os termos da Licença Creative Commons-Atribuição 4.0 Internacional. 